\title{
Reform of Teaching Mode of Basic Chemistry Experiment Course
}

\author{
Boquan Jiang ${ }^{*}$, Zhengping Chen, Bing Xiong, Deyou Wang, Ting Liu \\ Department of Biology and Chemistry \\ Institute of Science \\ Nanchang University College of Science and Technology, \\ Nanchang, Jiangxi, 330029 \\ China \\ *corresponding author. email: jbq_win@163.com. mobile phone number: 13397080986
}

\begin{abstract}
Reforming the teaching mode of fundamental chemistry experiment (FCE) course is important to realize the teaching target-cultivating the creative talents in the universities and colleges. For this goal, several measures are suggested in this paper: These measures involve "reforming the teaching contents, standing out the application and innovation; "reforming the teaching method, strengthening the students' innovation abilities" and "focusing on the development of comprehensive quality, improving the evaluation system of the FCE course. The practice of these methods achieved significant effects in correcting and changing the student's attitudes to experiment, increasing the student's experiment ability and cultivating the the student's good scientific style.
\end{abstract}

Keywords- reform, fundamental chemistry experiment; teaching mode, basic chemistry experiment; innovation

\section{I . INTRODUCTION}

Teaching mode can be defined as the stable teaching activity structure framework and activity programs established under the guidence of certain teaching ideas or teaching theory. Different education concept often puts forward different teaching mode. Any of teaching mode points to accomplish certain teaching target. In the structure of teaching mode, the teaching objective has a core position and plays a restriction role on the other factors constituting the teaching mode. The teaching objective decides the operation programm of the teaching mode and the combination relations between the teachers and students in teaching activities. The teaching objective is also as the criterion and scale of the teaching evaluation. It is because the strong internal unity between the teaching mode and teaching target decides the personality of different teaching mode. Different teaching mode serves certain teaching target. A complete new teaching mode should include the following five factors: the theoretical basis refering to the teaching theory or teaching ideas which is the basis of the teaching mode; the teaching goal refering to the results achieved by teaching mode ; the operating procedures refering to the activity links of teaching steps and the specific operation method of each step; the implementation conditions refering to the strategy, means, methods and skills of teaching and the evaluation refering to assessement of teaching quality. The FCE course is an important compulsory basic course opened for the majors of applied chemistry, biologic engineering, biologic technology, pharmaceutical engineering, polymer materials and engineering, environmental engineering and water supply and drainage in the college. The FCE course and the theoretical course of the fundamental chemistry are opend at the same time. The FCE course with strong practice can not only deepen the students understanding of the theoretical knowledge, but also make the students to correctly and craftily master the experimental principles and operation skills, develop their rigorous scientific attitudes and abilities of independently analyzing and solving practical problems[1-4]. The teaching target of independent college is to cultivate the applied and creative talents, for which, the traditional teaching mode of FCE course should be reformed and a new teaching mode suitable to the target should be established. In this paper, the reform measures of teaching mode of FCE course are discussed.

\section{II .REFORM ING THE TEACHING CONTENTS, STANDING OUT THE APPLICATION AND INNOVATION}

The target of independent college is to cultivate the senior applied talents with solid foundation, wide knowledge, high comprehensive quality, good innovative spirit and practicle ability. In order to realize this target, we design the experimental teaching contents by following considerations.

\section{A. Designing Teaching Contents Combined with the Reasonable Arrangement of Different Types of Experiments}

We designed the experimental teaching contents according to the thinking of " basic experiment $\rightarrow$ comprehensive experiment $\rightarrow$ series experiments $\rightarrow$ applied experiment $\rightarrow$ open experiment". The purpose of the "basic experiment" is to cultivate the students 
ability of grasping solid basic skills operations, such as washing glass instruments operation, material weighing operation, configuration operation of standard solution, titration operation, pipetting operation and the operations of $\mathrm{pH}$ meter, spectrophotometer and other basic instruments and equipment. The basic experiment projects include "the calibration of concentration of hydrochloric acid", "Measurement of the degree of ionization and dissociation constant of acetic acid", etc. in university chemistry experiments; " the thin layer chromatography", " the column chromatography", " extraction and separation of spinach pigment", etc., in organic chemistry experiments. The "comprehensive experiments" means the experiments selected based on the students having grasped the basic operation skills and basic unit operations. The purpose of the "comprehensive experiment" is to require the students to use multi-basic operation skills and unit operations to complete an experiment in order to increase their abilities of comprehensive experimental operation. The projects of comprehensive experiments include " the preparation of ammonium ferrous sulfate", " the determination of the mixed alkali", etc. in university chemistry experiments and " the synthsis of benzohydrol", etc. in organic experiments. The " series experiments" include two or more than two experiments. The previous experiment is the basis of the next experiment. The results of the previous experiment directly affect the results of the next experiment. The purpose of the " series experiments" is to further cultivate the students serious responsible and meticulous work spirit. The projects of series experiments include " the preparation of EDTA standard solution" and " the determination of water hardness" in university chemistry experiments and " preparation of ethyl acetate" and "the preparation of ethyl acetoacetate", etc. in organic chemistry experiments. The "applied experiment" means the experiments selected based on the basic experiments, comprehensive experiments and series experiments. The purpose of the "applied experiment" is to prepare practical products from the perspective of industrial applications and increase the students abilities of preparing and exploring industrial products. The applied experiments include " the purification of sodium chloride" in university chemistry experiments and " the synthesis of amino acid", etc. in organic chemistry experiments. The "open experiment" means the experiment independently completed by the students[5]. In the process, the teachers set the experiment subjects for the students to select. The students select the subjects and independently design the experimental schemes through searching literatures. After their experimental schemes are confirmed by the teachers, the students independently build the experimental devices, conduct the operations, treat the experimental dada, calculate the target values, write the experimental reports and report to the teachers by PPT files. The open experiment teaching mode gets rid of the traditional teaching mode of simplely doing verification experiment and realize the transform from the " teachers' teaching as the center" to the " students' autonomous learning as the center". The purpose of open experiment is to improve the students innovative consciousnesses and abilities. The open experiments are arranged to be done after all the other types of experiments have been completed. 8 of selected open experiments ( comprehensive and design type) are selected for both university chemistry experiments and organic chemistry experiments respectively, such as "The preparation of alkali type copper carbonate", " The determination of milk acidity and calcium content", "The synthesis of paracetamol", "The synthesis of dichloro", " The extraction of nicotine from tobacco ", " The extraction of berberine",etc.

\section{B Designing Teaching Contents Combined with the Industrial Production Processs}

Chemical unit operations (CUO) is common and important to the pharmaceutical factory, chemical factory and biological products factory. The CUO involves fluid conveying, filtration, stirring, sedimentation, heat transfer, absorption, distillation, extraction,crystallization,recrystallization,drying,evapor ation,etc. The CUO has follwing characteristics: ( i ) all the CUO are physical processes without reaction; (ii) all the CUO are the common operations in production process, however, the number, name and marshalling sequence of the CUO are different in different production processes; (iii) the basic principle of a unit operation is the same although it is used in different processes, and the equipment of CUO are commonly used. In our college, the selected subjects of FCE cover all the unit operations concerned above. The students can clearly understand the princiles of CUO and repeatedly do the same unit oprations in different experiments, which makes the students to familiar with the theories and operations of CUO and lay a solid foundation for the following courses of "chemical engineering principle" and "chemical engineering experiment" aand their future works.

\section{C.Designing Teaching Contents Combined with the Development of key disciplines}

With the rapid development of science and technology and the needs of the people life, some scientific areas are determined as key construction disciplines, such as materials, environmental protection, 
energy, food, life, medicine,etc. In order to make the students understand and concern on the development of the domestic and international frontier subjects and attract their interests in these disciplines, some experimental subjects related to these disciplines are selected.For example, the subject of " the measurement of water hardness" in university chemistry experiments is related to the discipline of environmental protection; the subject of " the Vc determination of pills" is related to the discipline of medicine; the subject of " the preparation of amino ethyl benzoate is related to the discipline of life; the subject of " the extraction of caffeine from tea" is related to the discipline of food; the subject of " the synthesis of 2 - methyl - 2 hexanol" is related to the discipline of materials. During the experiments, the teachers stress the importances of these disciplines and lead the students to pay close attention to these disciplines in future studies and researches.

\section{REFORMING THE TEACHING METHOD, STRENGTHENING THE STUDENTS INNOVATION ABILITIES}

The traditional teaching method of China universities and colleges is "teachers' teaching as the center", namely the "spoon-feeding" method of teaching. This old method could not adapt to the needs of training innovative talents and must be reformed. The key point is to realize the transform from the "teachers teaching as the center" to the "students" autonomous learning as the center". Some suggestions are proposed as follows.

\section{A.Taking the Students as the Main Body and Teachers as the Leading Factor}

It is important to change the traditional teaching method of "teaching as the center" into "studing as the center" in the teaching of FCE course. In the organization of experiment teaching, we actively advocate the new teaching method of the "students as the main body and the teachers as the leading factor" and boldly practice the transition from "teaching" as the center to the "learning" as the center. In the stage of preview, the teachers require the students to understand the purpose, principle and "thinking questions" of each experiment solely or through mutral discussions. Before the experiment, the students are arranged to ask and answer the questions each other, the teachers check the students preparations and detailedly explain the answers untill the students understand all the questions. During the experiments, the teachers ask the students to think, discuss and solve the problems appeared in their operations. The teachers encourage and praise the students who think hard and independently analyze and solve the problems, and patiently instruct the students who have some difficulties in the experimnts. Sometimes, the teachers ask some students to explain the experimental principles and " thinking questions" for the whole class and instruct the students who need the help for their non-standard operations. This method effectively plays the enthusiasm of the students' autonomous learning and improves the students abilities of independently thinking and solving practical problems

\section{B. Implementing the Open Experiment Combining Comprehensiveness with Designability}

The method of open experimental teaching indicates that the students independently complete their whole experiment procedure through their own thinking and exploration under the instruction of teachers[6-7]. This method is an important way to develop the student's potentials, increase the student's scientific quality and cultivate the student's innovative consciousnesses and abilities. In this semester, the open experiment of organic chemistry is being smoothly conducted. During the open experiment process, the students are required to select the experiment project prepared by the teachers and independently complete the project by various steps, such as independent literature review, making design scheme, predicting the needed chemicals and instruments, establishing experimental device, selfstarting work, treating data, writing small essays, reporting the experiment by PPT file, etc.. Mutual discussions and exchanges between the students and between the students and teachers are advocated. The laboratories provide the experimental place, time and instruments \& chemicals for the students to ensure the open experiment normally carried out. This teaching method can effectively cultivate the students comprehensive abilities of analyzing and solving practical problems, scientific research and innovation, resulting in the realization of the target of cultivating the high-quality application and innovative talents.

\section{Applying Modern Teaching Means and Combining Classroom Teaching with Extracurricular Learning}

With the in-depth development of the reform of modern teaching means of the college, the teaching of FCE course has realized the network teaching. The online teaching of FCE course has been conducted on the college network teaching platform.The teaching documents related the FCE course, such as "the multimedia courseware", "the collected thinking questions 
and answers", "the video demonstration on chemical basic operation skills", "the video demonstration on chemical unit operations" and "the collected comprehensive test questions" are loaded on the network teaching platform. The students can easily read them for preparing the course on-line or by downloading. The teachers load the subjects of the open experiments on the platform for the students to select and confirm the students experiment schemes on-line. The activities of asking and answering questions between the teachers and students can be carried out on the platform. The method of network teaching break through, on the one hand,the limitations of time and classroom in traditional teaching and extend the students time and space of studies. On the other hand, the imaginal and intuitive multimedia and video teachings become the single word explaination to the vivid illustrated forms, which greatly motivate the interests and enthusiasms of the students.

\section{D.Standardizing the Writing Experimental Report and improving the quality of report}

The quality of the experimental repors is the imporant basis for inspecting the experimental teaching quality. The teachers require the students to record and submit the experimental data on the spot, independently finish their reports, use their own words to describe the purposes, principles, steps of experiments, detailedly write down the experimental data and careflly treat the data. The teachers particularly require the students to focus on the analysis and discussions on the experiment results. The students who may make a failured experiment are asked to caerfully find the main reasons and redo the experiments. This kind of practice not only improve the students attentions on the FCE course, but also cultivate the students scientific attitude of seeking truth from facts and abilities of observation, analysis and solving practical problems.

\section{FOCUSING ON THE DEVELOPMENT OF COMPREHENSIVE QUALITY, IMPROVING THE EVALUATION SYSTEM OF FCE COURSE}

The evaluation on the teaching of FCE course is an important link in teaching activity[8-10]. It plays a key role in increasing teaching quality and has an important influence on the talent training. In order to improve the experimental teaching quality and train the advanced talents, we established a sceintific, objective and fair evaluation system to assess the students experimental abilities, including ( $\mathrm{i}$ ) grade of ordinary times (60 marks) involving the preview (10 marks), experimental operations and data treatment (25 marks), experimental attitudes (10 marks) and writing experiment report (15 marks). This comprehensive performance evaluation method can, to a certain extent, reflect the students practical abilities and levels, arouse and increase the students initiatives and enthusiasms of studies and plays an active role in improving the students ability to analyze and solve the practical problems, practical operation ability and comprehensive application ability.

\section{ACKNOWLEDGMENT}

This subject comes from " the Projects on Demonstration Laboratory Construction " financially supported by Nanchang University College of Science and Technology.

\section{REFERENCES}

[1] Xia Jingfen, Lin Jianyuan, Tang Li, Ying Min. "Reforming basic chemical experiment teaching model to cultivate high qualty talents". Experimental Science and Technology, 2008, issue 6, pp. 87-90.

[2] He Jianfeng, Wang Tao, Chen Chuanbing, Zhu Chenchen. "Study on the Modernization of the experimental teaching system for the fundamental chemistry". Experimental Science and Technology, 2010,8 , issue 5 , pp.84-85.

[3] Wang Xueying, Xu Xiaoxing and Li Qiaoyun. "The construction of system of basic chemical experimental teaching and evaluation based on the applied talents training ". .Journal of Changshu Institute of Technology, 2008, issue12, pp. 120-122.

[4] Li Xiulin, Cai Jiqing, Zeng Xiuqing, Zhao Huarong and $\mathrm{Fu}$ Chunlin. "Adhering to the people-centered to well do basic chemistry experiment teaching ".University Chemistry, 2011, Vol. 26, issue2, pp.:32-33,37.

[5] Li Hongmei, Lu Jiang and Wang Xianfeng. "Practice and summary of college basic chemical experiment teaching". University Chemistry, 2011, Vol. 26, issue 5, pp.39-42.

[6] Xu Yaqin, Fu Ying. "Research and exploration of open chemistry experiments". Experimental technology and management, 2007, issue 2, pp. 14-15.

[7] Wan Jian, Song Dandan, Tu Haiyang, et al. " Developing the students' comprehensive quality in the practice of basic chemistry experiment teaching". Experimental Technology and Management, 2012, Vol.29, issue 5, pp. 166-167.

[8] Wang Xueying, Xu Xiaoxing and Li Qiaoyun. "The construction of system of basic chemical experimental teaching and evaluation based on the applied talents training ". .Journal of Changshu Institute of Technology, 2008, issue12, pp. 120-122.

[9] Liu Kui, Wang Jianmin and Sun Hua. "Exploration and research on establishing a comprehensive evaluation system of the experimental results". GAO XIAO SHIYANSHI GONGZUO YANJIU, 2010, Vol. 104, issue2, pp. 32-33,77.

[10] Cui Hongshan, Xiong Ya,nlin. "Exploration and research of evaluation system of basic chemistry experiment teaching". Journal of Anhui University of Science and Technology(social science edition),2007, Vol. 9, issue4, pp. 85-88. 